\title{
Cold drawing schedules for RSt 34-2 (1.0034) steel wire for correction of overheating defects and breakless ensuring
}

\author{
Oleksandr Anishchenko1, Volodymyr Kukhar ${ }^{1, *}$, Iosyp Oginskiy $^{2}$, Maryna Korenko ${ }^{3}$, \\ Andrii Prysiazhnyi ${ }^{1}$ \\ ${ }^{1}$ Pryazovskyi State Technical University, Universytetska str., 7, Mariupol, 87555, Ukraine \\ ${ }^{2}$ Zaporizhzhia National University, Engineering Institute, Zhukovskogo str., 66, Zaporizhzhia, 69600, \\ Ukraine \\ ${ }^{3}$ Kryvyi Rih State University of Economics and Technology, Technological Institute, 5, \\ Stephana Tilhy Str., Kryvyi Rih, 50006, Ukraine
}

\begin{abstract}
The paper's authors researched the defects correction for RSt 34-2 (1.0034) steel wire, obtained as result of its overheating at $1140 \ldots 1160{ }^{\circ} \mathrm{C}$. Instead of the re-heat treatment method, the authors proposed five cold drawing, annealing and overheating combination schedules, which ensure the increase in strength to DIN EN ISO 6892-12020 requirements. The experiments were performed on $4 \mathrm{~mm}$ diameter wire with increased grain size (up to $70 \mu \mathrm{m}$ ). It was found that at low initial values of wire material's ultimate strength and yield strength there are frequent breaks of the wire at ends clamping by tongs. An equation that allows to predict the acceptable cross-sectional area of the wire end sections during drawing has been devised. An inequation for relating the Korber-Eichinger equation parameters and the wire ends sharpened sizes with reduced area due to the tongs jaws deepening after clamping the wire ends has been work out. The authors experimentally proved that the drawing overheated wire process designing taking into account the conditions of this inequation guarantees the elimination of breaks both at the wire end (at the drawing beginning) and at the process stable stage. The drawing processes for overheated wire have been developed eliminated the additional heat treatment operation to overheating defects correction.
\end{abstract}

\section{Introduction}

The analysis of wire drawing current state and prospects shows [1] that in the world there is a tendency to expand the range of materials by chemical composition, initial state, finishing mechanical properties and the attendant decrease in production. Development of drawing in small batches complex technologies, which also include improvement of operations previous and subsequent to drawing by using thermomechanical, pulse, electroerosion processing [2-6], determining optimal metal processing power schedules [7-10], allows to

\footnotetext{
* Corresponding author: kvv.mariupol@gmail.com
} 
make wire and deformed semi-finished products from operational properties and schedules [11-15], which are inaccessible to the multihole drawing machine. Achieving these goals is facilitated by the increasing use of mathematical modeling to assess the stress-strain and thermal state of materials, taking into account their plastic and thermophysical properties, accumulated damage and cracks, followed by assessment of their healing properties [1620]. Such materials to some extent reduce the stability of dies, but this is quite acceptable with low series and frequent changes in the range of forgings. Recycling of worn or defective wire is increasingly used [21, 22].

In particular, defects can occur when drawing steel wire with intermediate annealing, when it is possible to overheat individual wire coils. Due to the deterioration of mechanical properties, its further processing by pressure is almost impossible. Overheating defects are usually eliminated by additional heat treatment $[23,24]$, which increases the cost of the wire.

The purpose of this work is to develop cold drawing schedules of superheated wire, which ensure the metal continuity in the deformation process while increasing its strength.

\section{Materials and Methods}

The research included the RSt34-2 (EN 1.0034) steel wire with an initial diameter $\mathrm{D}=4 \mathrm{~mm}$, wound in coils weighing 1 ton each, which at $1140-1160{ }^{\circ} \mathrm{C}$ and exposure at this temperature for 3 hours were overheated. Cold drawing schedules were tested at drawing speeds from $2.25 \mathrm{~m} / \mathrm{s}$ in the first pass to $0.086 \mathrm{~m} / \mathrm{s}$ in the last passes. Annealing of the samples was performed in an electric furnace at $900-930^{\circ} \mathrm{C}$ for 2 hours. The mechanical properties of the wire were researched according to DIN EN ISO 6892-1-2020 on a machine P- 0.5 with a force of $5 \mathrm{kN}$.

Metallographic studies have shown that in the longitudinal and transverse sections of the wire, grains formed after overheating at $1140-1160{ }^{\circ} \mathrm{C}$ are small and equilibrium. Their diameter ranges from 6 to $24 \mu \mathrm{m}$ in the transverse and from 5 to $70 \mu \mathrm{m}$ in the longitudinal section of the wire, which indicates overheating of the metal under study.

Thermomechanical processing (TMP) of the wire was conducted by the following schedules:

(1) Cold drawing (properties correspond with DIN EN ISO 6892-1-2020);

(2) Cold drawing + annealing (properties correspond with DIN EN ISO 6892-1-2020);

(3) Cold drawing + overheating;

(4) Cold drawing + overheating + cold drawing;

(5) Cold drawing + overheating + cold drawing + annealing.

Wire properties after TMP are provided in table 1.

Overheating of the wire sharply reduces its yield ability: the drawing ratio of the samples is reduced by $4.5-10$ times compared to the limit value regulated by DIN EN ISO 6892-1-2020. Due to the thick layer of scale on the surface, ultimate strength and yield strength low values with abnormally low yield ability, the use of wire is impossible even as a binding material. The existing technological processes for drawing carbon steels turned out to be unacceptable: the wire could not be cleaned of scale, as repeated bending between the rollers of the machine led to its breakage. Etching of large coils in sulfuric acid did not remove scale on the turns of the wire located in the coils central part.

The most acceptable option for cleaning the surface of the wire was to pull it before entering the die holder through five worn wires with the initial working channel diameter equal to the wire diameter. In this case, the main layer of scale was lost in worn drawing die, and its remnants in the form of small grains fell off during the first drawing pass into the soap box when the wire entered the deforming die. 
Table 1. Wire mechanical properties after different schedules of TMP.

\begin{tabular}{|c|c|c|c|c|c|}
\hline $\begin{array}{c}\text { Wire } \\
\text { diameter, } \\
\text { mm } \\
\end{array}$ & $\begin{array}{c}\text { Schedule } \\
\text { number }\end{array}$ & $\begin{array}{l}\text { Ultimate } \\
\text { strength, } \\
\sigma, \mathrm{MPa} \\
\end{array}$ & $\begin{array}{c}\text { Yield } \\
\text { strength, } \\
\sigma, \mathrm{MPa} \\
\end{array}$ & $\begin{array}{c}\text { Percent } \\
\text { elongation, } \\
\delta, \% \\
\end{array}$ & $\begin{array}{c}\text { Percent } \\
\text { reduction, } \\
\psi, \% \\
\end{array}$ \\
\hline \multirow{3}{*}{4.0} & (1) & $440-530$ & - & - & - \\
\hline & (2) & $290-490$ & - & 20 & - \\
\hline & (3) & $361-372$ & $206-221$ & $2.0-4.6$ & $68-71$ \\
\hline \multirow{4}{*}{3.0} & (1) & $540-1080$ & - & - & - \\
\hline & (2) & $290-490$ & - & 20 & - \\
\hline & (4) & $581-598$ & $574-597$ & $3.3-4.0$ & $56-60$ \\
\hline & (5) & $283-290$ & - & $38-45$ & $62-65$ \\
\hline \multirow{4}{*}{2.55} & (1) & $540-1080$ & - & - & - \\
\hline & (2) & $290-490$ & - & 20 & - \\
\hline & (4) & $610-645$ & $595-618$ & $1.6-1.8$ & $51-56$ \\
\hline & (5) & $270-272$ & - & $37-40$ & $54-58$ \\
\hline \multirow{4}{*}{2.05} & (1) & $590-1180$ & - & - & - \\
\hline & (2) & $290-490$ & - & 15 & - \\
\hline & (4) & $723-765$ & $570-741$ & $2.0-3.3$ & $47-54$ \\
\hline & (5) & $269-277$ & - & $25.5-31.5$ & $50-56$ \\
\hline
\end{tabular}

Cold drawing of superheated wire in standard schedules was accompanied by frequent breaks, especially in the first pass. The frequency of breaks did not depend on the lubricant used. Considering this, the drawing on the first pass was later conducted without lubrication, and starting from the second pass, during the drawing of wire virtually clean from scale we used household soap dry powder.

Wire breaks during drawing occurred between the deforming die and the figure with the wire coil placed on it, in the tong jaws and between tongs and the deforming die. The reasons of wire breaks at its entrance to the deforming die were increased drawing speed, large coil mass and low yield strength of the wire material. At the initial moment of wire deformation at a drawing speed of $0.418 \mathrm{~m} / \mathrm{s}$, the back-pull load $Q$ required to unwind the coil on the support bearing of the figure, exceeded $2.5 \mathrm{kN}$. The back-pull stress, $\sigma_{Q}=Q / F_{0}$ (here $F_{0}$ is the cross-sectional area of the wire at the entrance to the deforming die) exceeded the yield strength of superheated steel (see table 1). This caused wire plastic deformation before its drawing and subsequent breakage due to low yield ability $(\delta=2.0-4.6 \%)$. The continuity of the metal was preserved by reducing the drawing speed to $0.245 \mathrm{~m} / \mathrm{s}$ and dividing the wire coil after the first drawing pass into coils weighing $60-80 \mathrm{~kg}$, which did not cause a significant surge of back-pull load in subsequent passes, even with a twofold increase in drawing speed.

Wire breaks in the tongs at the exit of the deforming die were eliminated by experimental selection of the optimal drawing speed $V$ and drawing ratio on the $i$-th pass $\left(\mu_{i}=d_{i-1}^{2} / d_{i}^{2}\right.$, where $d_{i-1}$ and $d_{i}$ are wire diameters before and after drawing on the $i$-th pass), taking into account the allowable wear of the die: the first pass $-V=0.245 \mathrm{~m} / \mathrm{s}$, $\mu=1.27-1.34$; the second pass $-V=0.418 \mathrm{~m} / \mathrm{s}, \mu=1.29-1.52$; the following passes $V=0.518 \mathrm{~m} / \mathrm{s}, \mu=1.20-1.38$.

\section{Results}

The mechanical properties of the wire with a diameter of 2.55 and $2.05 \mathrm{~mm}$ (see table 1), obtained by cold drawing in selected schedules, were acceptable for its further processing into nails or usage as a binding material. The increase in strength during cold drawing of wire with overheating defects was much more intense than during cold rolling of the same 
steel. The dependence of the wire ultimate strength and yield strength on the drawing ratio was approximated by the following equations:

$$
\sigma_{U}=366.9+560.0\left(1-\frac{1}{\sqrt{\mu}}\right)^{0.74} ; \sigma_{Y}=209.0+714.1\left(1-\frac{1}{\sqrt{\mu}}\right)^{0.63} .
$$

The data in table 1 show that the annealing of wire samples in the initial state and after cold drawing does not provide the required values of ultimate strength for DIN EN ISO 6892-1-2020, but substantially increases the percent elongation of the cold-worked wire, which allows it to be used for rivets and crooks.

Fig. 1 shows the dependences of the ultimate strength and yield strength on the wire drawing ratio. In the range of small drawing $(\mu \sim 3-4)$, these parameters increase quite intensively (by $1.5-1.75$ times). But the further increase in the drawing ratio does not so intensely affect the increase of wire mechanical properties. In addition, there is some convergence of ultimate strength and yield strength values.

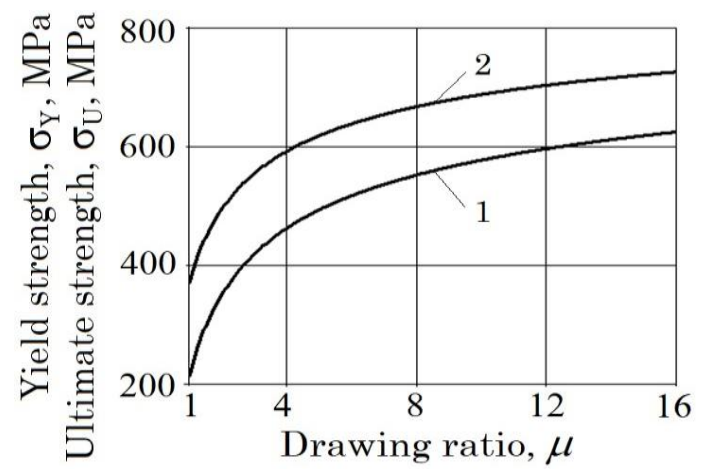

Fig. 1. Influence of the drawing ratio at the superheated wire drawing on ultimate strength (top curve) and yield strength (bottom curve) increase.

In order to predict the technological schedules of drawing substandard wire with other diameters and other steel grades based on the experiment results, the wire stress-strain state at the initial moment of drawing was researched.

After rolling in a grinding machine, the end section of the wire has a conical shape. At the tongs clamping point, its diameter is by $\Delta_{i}$ smaller than the diameter of the deforming die. Due to the RSt34-2 steel low yield strength and partly due to the wear of the grinding machine passes on the wire surface, longitudinal burrs are formed, which at the initial moment of drawing are either crumpled or cut by the die. In any case, in the contact area of the wire with the die deformation friction is maximum, i.e. the coefficient of friction $f=0.5$.

In the most unfavorable option for drawing, cutting burrs by the die in the calculations of the drawing force mode, the force of the cut should be taken into account, which is determined by the equation $[25,26]$ :

$$
P_{i}=1.4\left(\sigma_{\mathrm{U}}^{\mathrm{d}}\right)_{i} S,
$$

where $\left(\sigma_{U}^{d}\right)_{i}$ - wire material ultimate strength at the exit of the deforming die with the working diameter $d_{i} ; S$ - burr cut area.

Since at sharpening the ends of the superheated steel wire in the transition area $d_{i} \rightarrow\left(d_{i}-\Delta_{i}\right) \rightarrow d_{i+1}$, two diametrically opposite longitudinal burrs (Fig. 2) with 
dimensions $h$ and width $1.15\left(d_{i}-\Delta_{i}\right)$ are formed, during drawing with drawing ratio $\mu_{i}$ the specific force $p_{i}$ of the burr cutting will not exceed the values:

$$
p_{i}=K_{c} \mu_{i}\left(\sigma_{\mathrm{U}}^{\mathrm{d}}\right)_{i}
$$

where $K_{c} \sim 0.1$.

Experiments have shown that the coefficient $K_{c}$ depends on the wire material and is $\sim 0.14$ for cold-worked brass, $\sim 0.18$ for corrosion-resistant steel, $\sim 0.2$ for titanium.

The force developed by the drawing machine at the initial moment of deformation, causes in variable voltage in the area between tongs and deforming die along the length of the wire, the minimum of which is fixed at the exit of the die and is determined by the diameter $d_{i}$. In the area between the deforming die and tongs, this stress is by $d_{i}^{2} /\left(d_{i}-\Delta_{i}\right)^{2}$ times greater than the minimum. When clamping the wire, the tong jaws penetrate into the body of the wire on opposite sides to a depth of $\eta$ (see Fig. 2), the cross section of the wire in this place is reduced by:

$$
S_{R}=R^{2} \arccos \frac{R-\eta}{R}-\sqrt{2 R \eta-\eta^{2}}(R-\eta),
$$

Where $R$ - the radius of the wire pointed (sharpened) end, $R=\left(d_{i}-\Delta_{i}\right) / 2$.

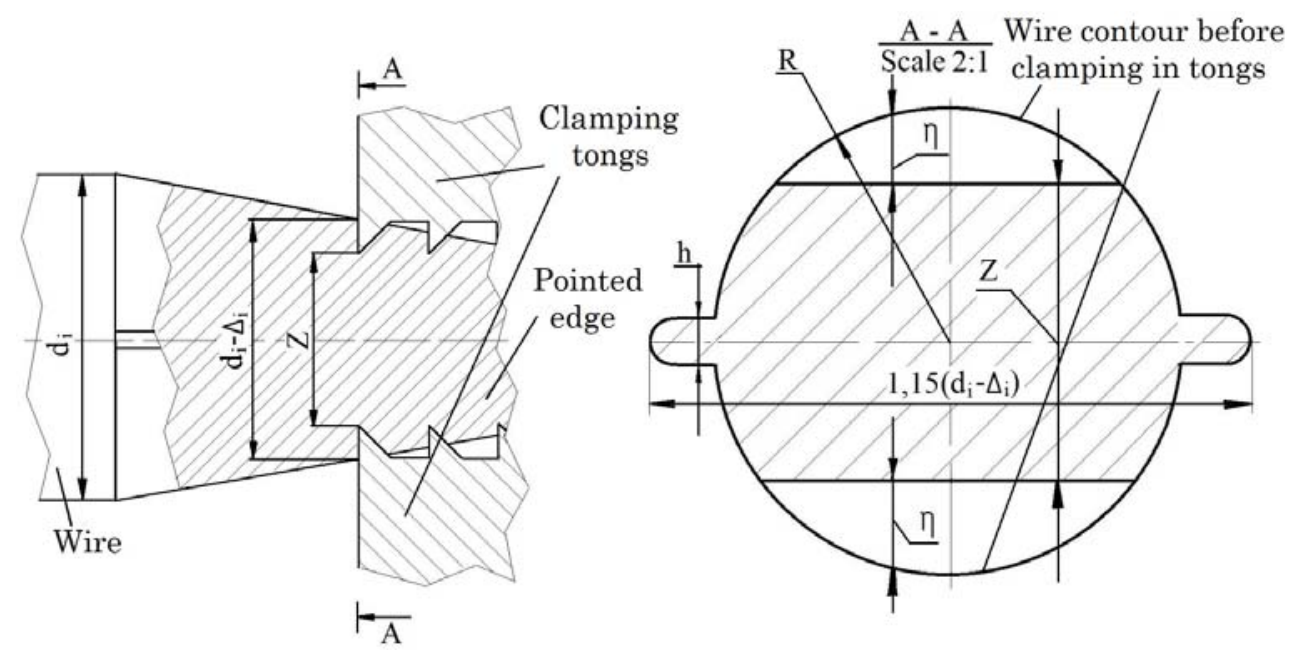

Fig. 2. Longitudinal (left) and transverse (right) sections of the wire pointed end clamped by tongs.

The distance $Z$ between the tong jaws, which penetrated into the body of the wire on opposite sides, is determined by the penetration depth $\eta$, which depends on the strength properties of the wire end sections.

Fig. 3 shows the relative change in the distance $Z$ depending on the decrease in wire diameter during drawing and subsequent pointing of its ends, i.e. from the total wire drawing ratio before immersion of the jaws when clamping the ends of the wire in the tongs.

The graphs show that for not overheated wire (upper curve) the distance $Z$ is almost not reduced, i.e. the strengthening of the wire during drawing has almost no effect on the immersion of the jaws into the wire body. 

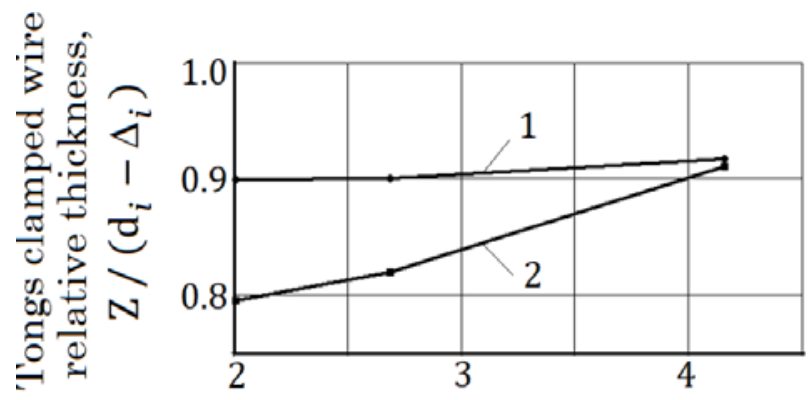

Drawing ratio, $\mu$

Fig. 3. Influence of the drawing ratio when drawing ordinary wire (1) and overheated wire (2) on the relative reduction of the distance between the tongs jaws, immersed in the wire body at its end section.

For overheated wire with its low strength values before drawing and with small elongations, tongs jaws penetrate into the body of the wire to a greater depth and significantly reduce the area calculated by equation (4). This difference causes frequent breaks of the overheated wire at the wire drawing initial stage exactly in the tongs, and not in the die or between the die and the machine drum.

Taking into account the measured values of $\eta$ during drawing on the $i-t h$ pass, the stress at the point of clamping the wire with tongs $\left(\sigma_{U}^{C}\right)_{i}$ will be $d_{i}^{2} / 0.8\left(d_{i}-\Delta_{i}\right)^{2}$ times greater than at the exit of the deforming die.

For the wire not to break in the tongs at the initial moment of drawing on the i-th pass, it is necessary to fulfill the condition:

$$
\left(\sigma_{U}^{C}\right)_{i}>p_{d}
$$

where $\left(\sigma_{U}^{C}\right)_{i}$ - ultimate strength at the point of wire clamping by tongs after pointing (sharpening) by rolling on diameter $d_{i}-\Delta_{i}$ with drawing ratio $\mu_{0}=D^{2} /\left(d_{i}-\Delta_{i}\right)^{2}$; $p_{d}$ - specific drawing force.

We shall use Korber and Eichinger equation $[27,28]$ to determine the specific drawing force and taking into account equation (3) we shall write the following inequality (5):

$$
\begin{gathered}
\frac{0.8\left(d_{i}-\Delta_{i}\right)^{2}}{d_{i}^{2}}\left(\sigma_{U}^{C}\right)_{i}> \\
\frac{\left(\sigma_{U}^{d}\right)_{i}+\left(\sigma_{U}^{d}\right)_{i-1}}{2}\left\{\frac{b}{a}\left[1-\left(\frac{1}{\sqrt{\mu_{i}}}\right)^{a}\right]+0,77 \operatorname{tg} \alpha\right\}+\sigma_{Q}\left(\frac{1}{\sqrt{\mu_{i}}}\right)^{a}+0,1 \mu_{i}\left(\sigma_{U}^{\mathrm{d}}\right)_{i},
\end{gathered}
$$

where $\left(\sigma_{U}^{d}\right)_{i-1}-$ ultimate strength of the wire on the i-th drawing pass before the entrance into deforming die; $a=\mathrm{f} \cdot \operatorname{ctg} \alpha ; b=1+\mathrm{f} \cdot \operatorname{ctg} \alpha ; \alpha$-die semiangle, $\alpha=7.5^{\circ}$.

Analysis of inequality (6) shows that the force condition of the drawing initial stage, which is determined by the right part of inequality (6), causes stresses in the wire cross section stipulated by burr shear force for $13-15 \%$ and back force for $30-35 \%$, the contribution of which is as higher, as bigger is the drawing ratio per pass. The coefficient of friction in this case is almost impossible to change, and the term $0.77 \operatorname{tg} \alpha$ at all values of $\alpha$ recommended for steels can be replaced by 0.1 . As $\Delta_{i}$ increases, although the metal ultimate 
strength in the area of sharpening increases, the value of the inequality left side (6) decreases.

\section{Discussion}

Thus, the main factors influencing the ultimate drawing of superheated wire with the strength characteristics stipulated by equations (1) is back force, specific burrs shear force and the difference between the deforming die diameter and the diameter of the wire pointed end.

Fig. 4 shows the calculation results of the drawing constant mode on the first pass using inequality (6). The graphs show that when the drawing speed is reduced from $0.418 \mathrm{~m} / \mathrm{s}$ to $0.245 \mathrm{~m} / \mathrm{s}$, the back force stress decreases from $203 \mathrm{MPa}$ to $163.8 \mathrm{MPa}$, the limit drawing ratio increases per pass from $1.025 ; 1.05$ and 1.108 to $1.09 ; 1.11$ and 1.17 , i.e. the diameter of the wire at the die exit can be reduced by $0.10-0.12 \mathrm{~mm}$. Qualitatively the same result can be obtained by reducing the difference between the diameter of the wire pointed (sharpened) end and the diameter of the die from $0.5 \mathrm{~mm}$ to $0.1 \mathrm{~mm}$. In this regard, to prevent wire breaks, it is advisable to choose the drawing routes, taking into account the available die of the rolls in the grinding machine. The diameter of the wire in each pass must be selected so that it does not exceed the diameter of its end section after sharpening in the appropriate die by more than $15 \%$. If it was possible to eliminate the crumpling and cutting of burrs on the wire $\left(p_{i}=0\right)$, the limit drawing ratio on the first pass would increase from 1.05 to $1.135\left(\sigma_{Q}=203 \mathrm{MPa}\right)$, as the route of drawing $4 \mathrm{~mm} \rightarrow 3.9 \mathrm{~mm}$ could be replaced by $4 \mathrm{~mm} \rightarrow 3.75 \mathrm{~mm}$.

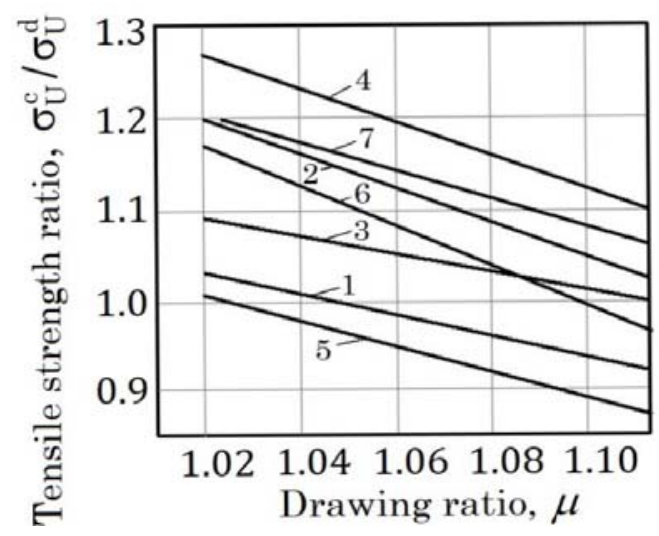

$$
\begin{aligned}
& 1-\Delta_{i}=0.5 \mathrm{~mm}, \sigma_{Q}=203.0 \mathrm{MPa} \\
& V=0.418 \mathrm{~m} / \mathrm{s} \\
& 2-\Delta_{i}=0.5 \mathrm{~mm}, \sigma_{Q}=163.8 \mathrm{MPa} \\
& V=0.245 \mathrm{~m} / \mathrm{s} ; \\
& 3-\Delta_{i}=0.1 \mathrm{~mm}, \sigma_{Q}=203.0 \mathrm{MPa} \\
& V=0.418 \mathrm{~m} / \mathrm{s} ; \\
& 4-\Delta_{i}=0.1 \mathrm{~mm}, \sigma_{Q}=163.8 \mathrm{MPa} \\
& V=0.245 \mathrm{~m} / \mathrm{s} ; \\
& 5-\mu_{0}=1.38, \sigma_{Q}=203.0 \mathrm{MPa} \\
& V=0.418 \mathrm{~m} / \mathrm{s} ; \\
& 6-\mu_{0}=1.38, \sigma_{Q}=163.8 \mathrm{MPa} \\
& V=0.245 \mathrm{~m} / \mathrm{s} ; \\
& 7-\Delta_{i}=0.5 \mathrm{~mm}, \sigma_{Q}=203.0 \mathrm{MPa} \\
& V=0.418 \mathrm{~m} / \mathrm{s}, p_{i}=0 .
\end{aligned}
$$

Fig. 4. The effect of the elongation $\mu$ on the stability of wire drawing in the first pass.

Practical verification of the strength criterion (5) showed its acceptability for the development of technology for drawing superheated wire. In particular, as can be seen in Fig. 4, the drawing ratio in one pass can be significantly increased by reducing the back force by forcibly untwisting the coil on the figure with a linear speed $20-30 \%$ smaller than the drawing speed $(V=0.245 \mathrm{~m} / \mathrm{s})$. In this case, the surge of the back force disappears, which allows to use deforming die with a diameter of $3.45 \mathrm{~mm}$ at $\Delta_{1}=0.25 \mathrm{~mm}$ at the first pass. 
Wire drawing in the second pass takes place in changed conditions. During rolling in the grinding machine, the diameter of the wire end is reduced to $2.52 \mathrm{~mm}$. Lubrication with soap powder helps to reduce the coefficient of friction from 0.5 to 0.1 at the drawing steady stage. With a lighter figure with a coil which does not weigh more than $80 \mathrm{~kg}$, at a drawing speed of $V=0.418 \mathrm{~m} / \mathrm{s}$, the back force is reduced to $46 \mathrm{MPa}$. Under these conditions, the calculation according to the strength criterion (5) provides a limit drawing ratio on the second pass $\mu_{2}=1.52$ along the route of drawing $3.45 \mathrm{~mm} \rightarrow 2.80 \mathrm{~mm}$, for which $\left(\sigma_{U}^{c}\right)_{2} /\left(\sigma_{U}^{d}\right)_{2}=1.03$.

On the third pass it is necessary to make a wire with a diameter of $2.55 \mathrm{~mm}$, which is carried out with a drawing speed of $0.518 \mathrm{~m} / \mathrm{s}$. Under drawing conditions, it is allowed to reduce the diameter of the deforming die to $2.32 \mathrm{~mm}$.

On the fourth pass it was impossible to draw the wire along the route $2.55 \mathrm{~mm} \rightarrow 2.05 \mathrm{~mm}$, because due to the sharpening of the wire end with a diameter of $1.67 \mathrm{~mm}$, it broke in the tongs at the drawing initial moment. Verification of this experimental fact by analytical calculations for inequality (6) confirmed the probability of wire breakage: $\left(\sigma_{U}^{c}\right)_{i} /\left(\sigma_{U}^{d}\right)_{i}=0.88$. In this regard, the drawing routes on the fourth and fifth passes $2.55 \mathrm{~mm} \rightarrow 2.32 \mathrm{~mm} \rightarrow 2.05 \mathrm{~mm}$ were chosen based on the presence of a deforming die with a diameter of $2.32 \mathrm{~mm}$. It should be noted that the fifth pass could be avoided if the grinding machine had a caliber with a diameter of $1.8 \mathrm{~mm}$.

\section{Conclusions}

The cold drawing technology of superheated wire from RSt34-2 steel without repeated annealing is developed. At drawing ratio of $1.20-1.52$ on one pass and drawing speeds from $0.245 \mathrm{~m} / \mathrm{s}$ to $0.518 \mathrm{~m} / \mathrm{s}$, this provides the increase of strength to level sufficient for using a wire as a binding material and nails billets.

Based on experimental data, the analytical dependences of the ultimate strength and yield strength of the superheated wire on its drawing ratio during drawing were obtained.

The inequality is proposed, which connects the stress that occurs at the initial moment of drawing in the cross section of the wire end pointed section, and the burrs shear stress formed during sharpening, with the ultimate strength of RSt34-2 (EN 1.0034) steel. The inequality allows to calculate the limit drawing ratio on each drawing pass.

\section{References}

1. A.A. Radionov, L.V. Radionova, Russian Internet Journal of Industrial Engineering 1, 3-11 (2013)

2. V. Tarelnyk, V. Martsynkovskyy, O. Gaponova et al., IOP Conf. Ser.: Mater. Sci. Eng. 233, 012048 (2017)

3. V.I. Zurnadzhy, V.G. Efremenko, I. Petryshynets et al., Kovove Materialy 58, 129-140 (2020)

4. L.S. Malinov, I.E. Malysheva, E.S. Klimov et al., Materials Science Forum 945, 574-578 (2019)

5. V. Dragobetskii, V. Zagirnyak, S. Shlyk et al., Przeglad Elektrotechniczny 95(5), 39-42 (2019)

6. A.S. Anishchenko, A.P.Andryushchenko, Soviet Engineering Research 11(5), 95-97 (1991) 
7. D. Yarymbash, M. Kotsur, Y. Bezverkhnia, S. Yarymbash, I. Kotsur, IEEE 3rd Int. Conf. on Intelligent Energy and Power Systems (Kharkiv, IEPS, IEEE), 76-79 (2018) doi:10.1109/IEPS.2018.8559576

8. A.S. Anishchenko, N.Yu. Sosnovskij, Kuznechno-Shtampovochnoe Proizvodstvo 11, 27-28 (1993)

9. S.O. Korol, M. Moroz, S.S. Korol, V. Yelistratov, O. Moroz, Int. Conf. on Modern Electrical and Energy Systems (Kremenchuk, MEES, IEEE), 30-33 (2019) doi:10.1109/MEES.2019.8896485

10. V.I. Kaplanov, A.G. Prisyazhnyi, Steel in Translation 38(9), 714-718 (2008)

11. V.V. Kukhar, A.V. Grushko, I.V. Vishtak Solid State Phenomena 284, 408-415 (2018)

12. A.S. Anishchenko, Y.V. Feofanov, A.B. Bogun, Khimicheskoe I Neftegazovoe Mashinostroenie 11, 33-35 (1992)

13. O. Markov, O. Gerasimenko, L. Aliieva et al., Eastern-European Journal of Enterprise Technologies 2(1)(98), 39-46 (2019)

14. N. Hrudkina, L. Aliieva, P. Abhari et al., Eastern-European Journal of Enterprise Technologies 2(5-1)(101), 49-57 (2019)

15. N.S. Hrudkina, L.I. Aliieva, FME Transactions 48(2), 357-363 (2020)

16. V. Kukhar, O. Kurpe, E. Klimov et al., International Journal of Engineering \& Technology (UAE) 7(4.3), 35-39 (2018)

17. O. Trotsko, S. Shlyk, IEEE 13th Int. Sci. Tech. Conf. on Computer Sciences and Information Technologies 1, 169-172 (2018) doi:10.1109/STC-CSIT.2018.8526614

18. I.K. Oginskiy, Metallurgical and Mining Industry 7, 20-26 (2011)

19. T. Chereches, P. Lixandru, S. Mazuru et al., Academic Journal of Manufacturing Engineering 12(2), 29-36 (2014)

20. I.P. Shats'kyi, Materials Science 51(3), 322-330 (2015)

21. A.S. Anishchenko, Metallovedenie i Termicheskaya Obrabotka Metallov 4, 31-32 (1996)

22. O. Anishchenko, E. Balalayeva, V Kukhar et al., Int. Conf. on Modern Electrical and Energy Systems (Kremenchuk, MEES, IEEE), 482-485 (2019) doi:10.1109/MEES.2019.8896433

23. G.E. Totten, Steel Heat Treatment: Metallurgy And Technologies (Taylor \& Francis Group, 2006)

24. S.A. Kumar, Defects and Distortion in Heat-Treated Parts (ASM Handbook, 1991)

25. M. Greger, Forging (Ostrava, VSB-TU, 2014)

26. Y.M. Okhrimenko, Forging \& stamping production (Moscow, Engineering, 1976)

27. F. Körber, U.A. Eichinger, Mitt. Kais. Wilh. Inst. Eisenforsch 22, 57 (1940)

28. R. Hill, The Mathematical Theory of Plasticity (Oxford, University Press, 1998) 